\title{
Epidemiology of women diagnosed with breast cancer in Jordan
}

\author{
A 5-year survival analysis and patients' characteristics from 2 public \\ hospitals
}

Rimal H. Mousa, MSc, PhD, Jamal M. Melhem, MD, FRCCS, Eman A. Hammad, MSc, PhD.

\begin{abstract}
الأهداف : قياس معدل النجاة خلال خمس سنوات لدى المصابات بسرطان الثدي

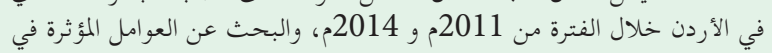

ذنلك.

المنهجية : أجريت هذه الدراسة بأثر رجعي وقد شملت الدراسة جميع الأردنيات

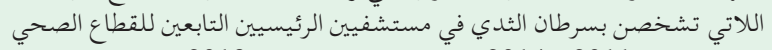

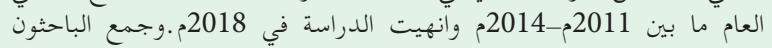

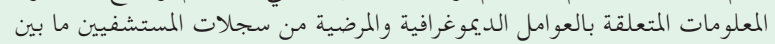
.2018,2011

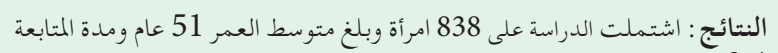

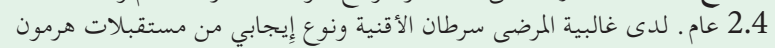

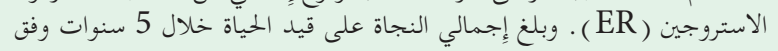

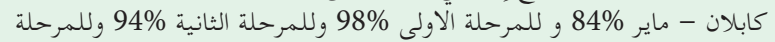

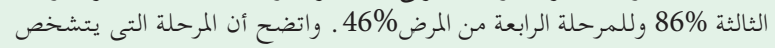

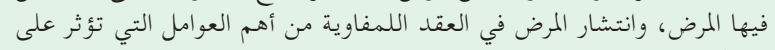

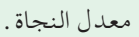

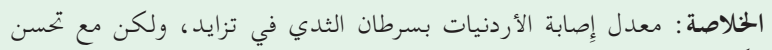

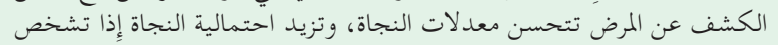

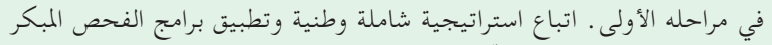

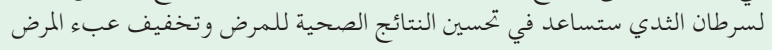

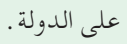

Objectives: To evaluate the epidemiology, prognostic factors, and 5-year overall survival (OS) of females with breast cancer (BC) diagnosed between 2011 and 2014 in Jordan.

Methods: A retrospective medical review of females who were diagnosed with BC between 2011 and 2014 at the 2 leading public health providers in Jordan was performed. The endpoint of the study was 2018. Data were extracted from the medical files between 2011 and 2018, including demographic clinical data on the patient level. Survival by age, laterality, grade, stage, and treatments modes were calculated by the Kaplan Meier method.
Results: A total of 877 women were included with median age of 51 years and follow-up duration of 2.4 years. Majority of the patients had ductal carcinoma and estrogen receptor (ER) positive type. The 5-year OS for patients with stage I, II, III, and IV, 94\%, 86\%, and $46 \%(p<0.001)$, respectively. The tumor stage and nodal status were the main prognostic variables affecting the overall survival.

Conclusion: The incidence in Jordan is increasing, yet survival rates are improving with increased diagnosis during early stages. Therefore, strategies for implementing universal screening programs are advocated to improve clinical outcomes and to reduce the disease burden.

Keywords: breast neoplasm, survival, epidemiology, prognosis, Jordan

Saudi Med J 2021; Vol. 42 (7): 776-783

doi: 10.15537/smj.2021.42.7.20210112

From the Department of Biopharmaceutics and Clinical Pharmacy (Mousa, Hammad); and from the Department of General Surgery (Melhem), Faculty of Medicine-University of Jordan, Amman, Jordan.

Received 4th May 2021. Accepted 8th June 2021.

Address correspondence and reprint request to: Dr. Rimal H. Mousa, Department of Biopharmaceutics and Clinical Pharmacy, School of PharmacyUniversityofJordan,Amman,Jordan.E-mail:r.mousa@ju.edu.jo ORCID ID: https://orcid.org/0000-0002-1788-0281

Disclosure. This study was supported by the Deanship of Scientific Research at the University of Jordan, Amman, Jordan (Grant No. 2018-2017/107). The funding body did not play any role in the design of the study, the analysis, or the interpretation of the data since it was an unrestricted funding. 
$\mathrm{B}$ reast cancer $(\mathrm{BC})$ is the main cancer type (24.2\% of cancer cases) in women across the world. ${ }^{1}$ Developing countries, such as countries in the Eastern Mediterranean region (EMR), varied in cancer incidence and mortality rate, 2 and similarly $\mathrm{BC}$ is the main type of cancer 2 with 95 thousands newly cancer cases were reported from 6 national cancer registries in the EMR between 1998 and 2007. ${ }^{3}$ This numbers is potentially underestimated due to lack of documentation and quality of data. ${ }^{2}$

Jordan is a country located in the EMR with uppermiddle-income level, with a population of 10.20 million cancer accounting for $12 \%$ of all cases of death in 2016 in Jordan. ${ }^{4,5}$ Several retrospective studies described the epidemiology and patients' characteristics of $\mathrm{BC}$ in Jordan and how they are linked with patients' survival. ${ }^{6,7}$ However, these studies were published a decade ago and did not included all patients' characteristics that may affect survival. Nevertheless, these studies outlined increasing in cancer incidence, and highlighted that the cancer patterns are changing rapidly in Jordan. Overall survivals (OS) were shown to improve over the years too. Of note, the tumor stage was often shown as a leading factor to survival outcome. ${ }^{6-8}$ However, this was concluded without consideration of cancer staging and estrogen receptor (ER), progesterone receptor (PR), and human epidermal receptor (HER2) status, tumor size, smoking, marital status, menopausal status, type of treatment, age, tumor grade, laterality, degree of ER positivity, lymph node status (tumor, nodal, and metastasis [TNM]) on OS. Thus, comprehensive assessment of factors and drivers is warranted.

Cancer treatment is offered at subsidized costs by public providers in Jordan which is mainly franchised by the government fund and tax payers. The composite of the public sector in Jordan is the Ministry of Health $(\mathrm{MOH})$, the military's Royal Medical Services (RMS), and 2 university hospitals. The $\mathrm{MOH}$ is the leading health provider for cancer treatment for civil employees and their dependents, accounting for almost $40 \%$ of cancer cases, according to the Jordan Cancer Registry's (JCR) data accessed from the Jordan $\mathrm{MOH}$ records. Jordan Cancer Registry is a population-based registry established in 1996 under the domain of $\mathrm{MOH}$. Cancer notification is compulsory since 1996 through a ministerial decree from all possible notification sites in the kingdom including both public and the private. Jordan Cancer Registry monitor cancer incidence in Jordan and trends over time. Referral cases are treated by other providers, including university hospitals (5\%) and RMS (15\%), where treatment modalities are not available within the $\mathrm{MOH} .{ }^{9,10}$ Although approximately
$30 \%$ of cases are treated at King Hussein Cancer Center $(\mathrm{KHCC}){ }^{8}$ this represents cases for those that are well off. This study evaluated the epidemiology, 5-year OS, and prognostic factors related to $\mathrm{BC}$ in the 2 leading public hospitals in Jordan to underpin the status of cancer care and strategies to improve prognosis and to reduce the disease burden

Methods. Ethical approval was obtained from the medical ethics committee of the $\mathrm{MOH}$, Bashir, and University of Jordan Hospital (UJH), Amman, Jordan before starting data collection and in concordance with Declaration of Helsinki. Patientswere not consented since the information was not directly collected from patients. This retrospective medical review included females with Jordanian nationality and diagnosed with $\mathrm{BC}$ in 2 central public hospitals in Amman, the capital of Jordan; UJH and Bashir Hospital between 2011 and 2014. Data were obtained from hospital records and the JCR from 2011 to 2018. The JCR has been established since 1996 under the provision of the $\mathrm{MOH}$, and it collects all cancer data from all health care providers in Jordan, including all governmental hospitals, private hospitals, RMS, and university hospitals. ${ }^{11}$ The UJH is a leading public hospital in Amman, Jordan where half of the population reside in. In addition to its contribution as major referral hospital for patients living in the remote governances. ${ }^{12}$ Bashir Hospital is the biggest governmental hospital in Jordan that treats cancer patients, with separate departments including radiotherapy and chemotherapy. ${ }^{11}$ Socio-demographic characteristics, tumor characteristics, and clinical outcomes (overall death) were also obtained from JCR and hospital medical files.

Only female cases with Jordanian nationality diagnosed with BC between 2011 and 2014 were included. Male patients with other nationality such as refugee were excluded. In addition, patients whom their medical files could not be reached or were not diagnosed between 2011-2014 were also excluded.

Following the diagnosis with $\mathrm{BC}$, each patient was followed until the end of study period (April 2018) unless they died or lost contact. Data on the above mentioned variables was collected by a research assistant and filled in a data collection sheet designed in Micsrosoft Excel 2016. Patient information was handled confidentially and anonymously using the patients' national numbers.

Prior related research has been identified from the PubMed database using the medical subject heading $(\mathrm{MESH})$ terms and free text related to breast cancer ("breast neoplasms/drug therapy, economics, mortality, radiotherapy, surgery, therapy" [MESH] OR 
"carcinoma, ductal, breast/drug therapy, economics, mortality, radiotherapy, surgery, therapy" $[\mathrm{MESH}]$ OR ([early or primary or operable or early stage or stage I or stage II adj (breast adj (adenocarcinoma* or cancer* or carcinoma* or neoplasm* or tumor) AND MESH and free text related to epidemiology ("disease-free survival/ or survival analysis/ or survival/ or survival rate/"[MESH] OR (surviv* or mortalit* or epidemiology)). In addition to a free text of Jordan and Middle East was used".

Statistical analysis. The analysis was performed using STATA/SE, version 15. The demographic, tumor characteristics, and treatments offered to patients were summarized. The change in OS probabilities with time (such as, 1- and 5-year OS), in addition to survival probabilities adjusted by age, ER status, nodal status, stage, and treatment, were performed by the Kaplan Meier (KM) method. The associations between these factors and OS were tested by log rank test. ${ }^{13,14}$

The OS rate adjusted by prognostic factors was performed by Cox proportional hazard regression with a stepwise backward elimination approach. ${ }^{13,15}$ Initially, all the previously discussed prognostic factors discussed previously were considered in the model, ${ }^{6,16-21}$ and then excluded one at a time based on the least significant variables until all the remaining variables were significant. The results of Cox's regression are presented as a hazard ratio (HR) for each covariate with $95 \%$ confidence interval (95\% CI), and a $p$-value $<0.05$ indicating a statistically significant association.

Since the Cox model assumes a constant HR over time, ${ }^{15,22}$ this was checked using the Schoenfeldresiduals test, with $p<0.05$ indicating violation of the proportional hazard assumption, and, thus, a timevarying interaction expression was added to imply the non-proportionality of the HR. For the variables with proven time-varying effect, the estimated variable effect on the mortality rate at a particular time point was obtained using the following formula: (hazard ratio) $\mathrm{HR}=\mathrm{HR}$ (main effect) ${ }^{*} \mathrm{HR}$ (time varying effect) $(\mathrm{t})$,

Where HR (main effect) is the HR for the main variable effect, $H R$ (time varying effect) is the time varying $H R$ for the variable, and $t$ is the particular time point.

Results. The distribution of BC cases by demographic and clinical characteristics is presented in Table 1 and Table 2. A total of 877 patients were included in the analysis. Approximately half of the cohort were diagnosed within the age group of 40-59 years. The median age was 51 years (interquartile range [IQR]: 43-60). The majority of the patients were married and non-smokers.
The left and right sides of the breast were equally affected (Table 2). Approximately $87 \%$ of the patients were diagnosed with ductal carcinoma. Approximately, $45 \%$ of patients showed moderate differentiation, whilst $0.5 \%$ showed well-differentiation. The majority of the tumors had a positive ER and PR receptor type and $49 \%$ have negative HER2 status. Half of the patients has luminal A subtype. More than half of the tumors did not spread to the axillary lymph nodes. The tumor size was $<5 \mathrm{~cm}$ in $63.8 \%$ of the cases; $15.1 \%$ had stage I, $28.8 \%$ had stage II, 36\% had stage III, and $14.1 \%$ had stage IV. According to the treatment received, approximately $33.1 \%$ received surgical therapy combined with 2 adjuvant therapy (endocrine

Table 1 - The percentages of breast cancer cases stratified by tumor characteristics.

\begin{tabular}{|c|c|c|}
\hline Demographic' characteristics & n & $(\%)$ \\
\hline \multicolumn{3}{|l|}{ Age (years) } \\
\hline$<30$ & 18 & $(2.1)$ \\
\hline $30-39$ & 113 & $(12.9)$ \\
\hline $40-49$ & 275 & $(31.4)$ \\
\hline $50-59$ & 241 & $(27.5)$ \\
\hline $60-69$ & 166 & $(19.0)$ \\
\hline$>70$ & 63 & $(7.2)$ \\
\hline \multicolumn{3}{|l|}{ Menopausal status } \\
\hline Premenopausal & 433 & $(49.4)$ \\
\hline Postmenopausal & 444 & $(50.6)$ \\
\hline \multicolumn{3}{|l|}{ Marital status } \\
\hline Single & 56 & $(6.4)$ \\
\hline Widowed & 31 & $(3.5)$ \\
\hline Married & 761 & $(86.8)$ \\
\hline Divorced & 14 & $(1.6)$ \\
\hline Unknown & 15 & $(3.5)$ \\
\hline \multicolumn{3}{|l|}{ Smoking status } \\
\hline Non smoker & 630 & $(71.8)$ \\
\hline Smoker & 21 & $(2.4)$ \\
\hline Past smoker & 53 & $(6.0)$ \\
\hline Unknown & 19.73 & $(19.7)$ \\
\hline \multicolumn{3}{|l|}{ Comorbidities } \\
\hline 0 & 592 & $(67.5)$ \\
\hline 1 & 140 & $(16.0)$ \\
\hline 2 & 98 & $(11.2)$ \\
\hline 3 & 34 & $(3.9)$ \\
\hline 4 & 13 & $(1.5)$ \\
\hline \multicolumn{3}{|l|}{ Treatment } \\
\hline Surgery & 83 & $(9.5)$ \\
\hline Surgery plus systemic adjuvant & 217 & $(24.7)$ \\
\hline Surgery plus radiotherapy & 202 & $(23.0)$ \\
\hline Surgery plus 2 adjuvant & 290 & $(33.0)$ \\
\hline Surgery plus 3 adjuvant & 19 & $(2.2)$ \\
\hline Non-surgical treatment & 66 & $(7.53)$ \\
\hline \multicolumn{3}{|l|}{ Vital status } \\
\hline Alive & 777 & $(88.6)$ \\
\hline Dead & 100 & $(11.4)$ \\
\hline
\end{tabular}


Table 2 - The percentages of breast cancer cases stratified by tumor characteristics.

\begin{tabular}{|c|c|c|}
\hline Tumor characteristics & $\mathrm{n}$ & $(\%)$ \\
\hline \multicolumn{3}{|l|}{ ER status } \\
\hline Negative & 163 & (18.6) \\
\hline Positive & 576 & $(65.7)$ \\
\hline Unknown & 138 & $(15.7)$ \\
\hline \multicolumn{3}{|l|}{ PR status } \\
\hline Negative & 249 & $(28.4)$ \\
\hline Positive & 423 & $(49.0)$ \\
\hline Unknown & 198 & $(22.6)$ \\
\hline $\begin{array}{l}\text { Molecular subtype } \\
\text { Luminal A }\end{array}$ & 428 & $(48.8)$ \\
\hline Luminal B & 108 & (12.3) \\
\hline Triple negative & 101 & (11.5) \\
\hline HER2 positive & 69 & $(7.9)$ \\
\hline Unknown & 171 & $(19.5)$ \\
\hline \multicolumn{3}{|l|}{ Grade based on $N C B$} \\
\hline 1 (well-differentiation) & 28 & $(3.2)$ \\
\hline 2 (moderately differentiation) & 393 & $(44.8)$ \\
\hline 3 (poorly differentiation) & 248 & $(28.3)$ \\
\hline 4 (undifferentiation) & 4 & $(0.5)$ \\
\hline Unknown & 204 & (23.3) \\
\hline \multicolumn{3}{|l|}{ TNM staging } \\
\hline 0 (in situ) & 10 & $(1.1)$ \\
\hline I & 132 & $(15.1)$ \\
\hline II & 253 & $(28.9)$ \\
\hline III & 316 & $(36.0)$ \\
\hline IV & 124 & $(14.1)$ \\
\hline Unknown & 42 & $(4.8)$ \\
\hline \multicolumn{3}{|l|}{ Clinical tumor size } \\
\hline$<5$ & 560 & $(63.9)$ \\
\hline $5.1-10$ & 198 & (22.6) \\
\hline $10.1-15$ & 29 & $(3.3)$ \\
\hline $15.1--25$ & 3 & $(0.3)$ \\
\hline Unknown & 87 & (9.9) \\
\hline \multicolumn{3}{|l|}{ Lymph node status (NCB) } \\
\hline Positive & 229 & $(26.1)$ \\
\hline Negative & 540 & (61.6) \\
\hline Unknown & 108 & (12.3) \\
\hline \multicolumn{3}{|l|}{ Histological type } \\
\hline Ductal & 762 & $(86.9)$ \\
\hline Lobular & 37 & $(4.2)$ \\
\hline Mixed lobular and ductal & 5 & $(0.6)$ \\
\hline Medullary & 6 & $(0.7)$ \\
\hline Carcinoma NOS & 12 & (1.4) \\
\hline Adenocarcinoma & 4 & $(0.5)$ \\
\hline Other types & 51 & $(5.8)$ \\
\hline \multicolumn{3}{|l|}{ Site of breast } \\
\hline Bilateral & 3 & $(0.3)$ \\
\hline Left & 422 & $(48.2)$ \\
\hline Right & 422 & (48.2) \\
\hline Unknown & 29 & $(3.3)$ \\
\hline
\end{tabular}

ER: estrogen receptor, HER2: human epidermal receptor, NCB: needle core biopsy, NOS: not otherwise specified, PR: progesterone receptor, TNM: tumor, nodal, metastasis. Well differentiation cancer refers to cancer cell that look like normal cell whereas moderate differentiation somehow look like normal cell. The more the similarity of cancer cell appearance to the healthy one, the lower the tumor grade is. Tumors with low grade are associated with less aggressive prognosis treatment, chemotherapy, or radiotherapy) (Table 2). The median follow-up duration ranged between one and 5 years (median of 2.4 years). Of the patients, $88.6 \%$ were known to be alive during the follow-up duration (Table 2).

The 1- and 5-year OS are illustrated in Figure 1A. Using the KM method, the percentages of women surviving $1,2,3,4$, and 5 years after being diagnosed with BC were $94 \%, 87 \%, 85 \%, 84 \%$, and $84 \%$, respectively. Overall survival by age, ER status, nodal status, type of treatment, and tumor stage are illustrated in Figure 1B-1F. The 5-year OS was the highest for the 40-49 years age group, whereas the lowest 5-year OS were in the $>70$ years age group $(p=0.015)$. The 5 -year OS for patients with ER-positive was higher than patients with ER-negative status $(p<0.001)$. Patients with negative nodal status was associated with lower 5-year OS as compared to positive nodal status $(p=0.001)$.

Based on tumor stage, the 5-year OS for patients with stage III and IV were lower than patients with stage I and II $(p<0.001)$. Patients who received surgery combined with 2 adjuvant therapies showed higher OS compared to those who received surgery with one adjuvant therapy $(p<0.001)$.

The result of the Cox regression is presented in Table 3. Tumor and demographic characteristics were considered potential prognostic confounders in the model. However, only age, ER, tumor size, tumor stage, and lymph node status were found to be significant contributors for the OS and, thus, were kept in the model. In addition, the proportional hazard assumption was violated for lymph node status, implying that its effect on the OS varied over time (Table 3). Tumor, nodal, metastasis staging $(p<0.001)$ and ER status $(p<0.001)$ strongly affected the survival. Patients with stage I had a significantly better OS when compared with other stages $(p \leq 0.001)$. Patients with positive ER $(p<0.001)$ had significantly better OS compared with the patients with negative ER status.

In addition, there was a significant increase in the overall death by $40 \%$ with each one $\mathrm{cm}$ increase in the tumor size. Patients with negative lymph node status had a better OS compared with positive lymph node status $(p=0.068)$. However, the higher risk of overall death associated with positive lymph node status as compared to negative one decreased by $76 \%$ (timevarying HR: $0.24 ; 95 \%$ CI: $0.08,0.76$ ) for each year of follow-up time.

Patients within the age group of 40-49 years had better OS compared with other age groups, whereas patients aged $<30$ or over 70 years were significantly associated with the lowest OS $(p=0.003)$. 

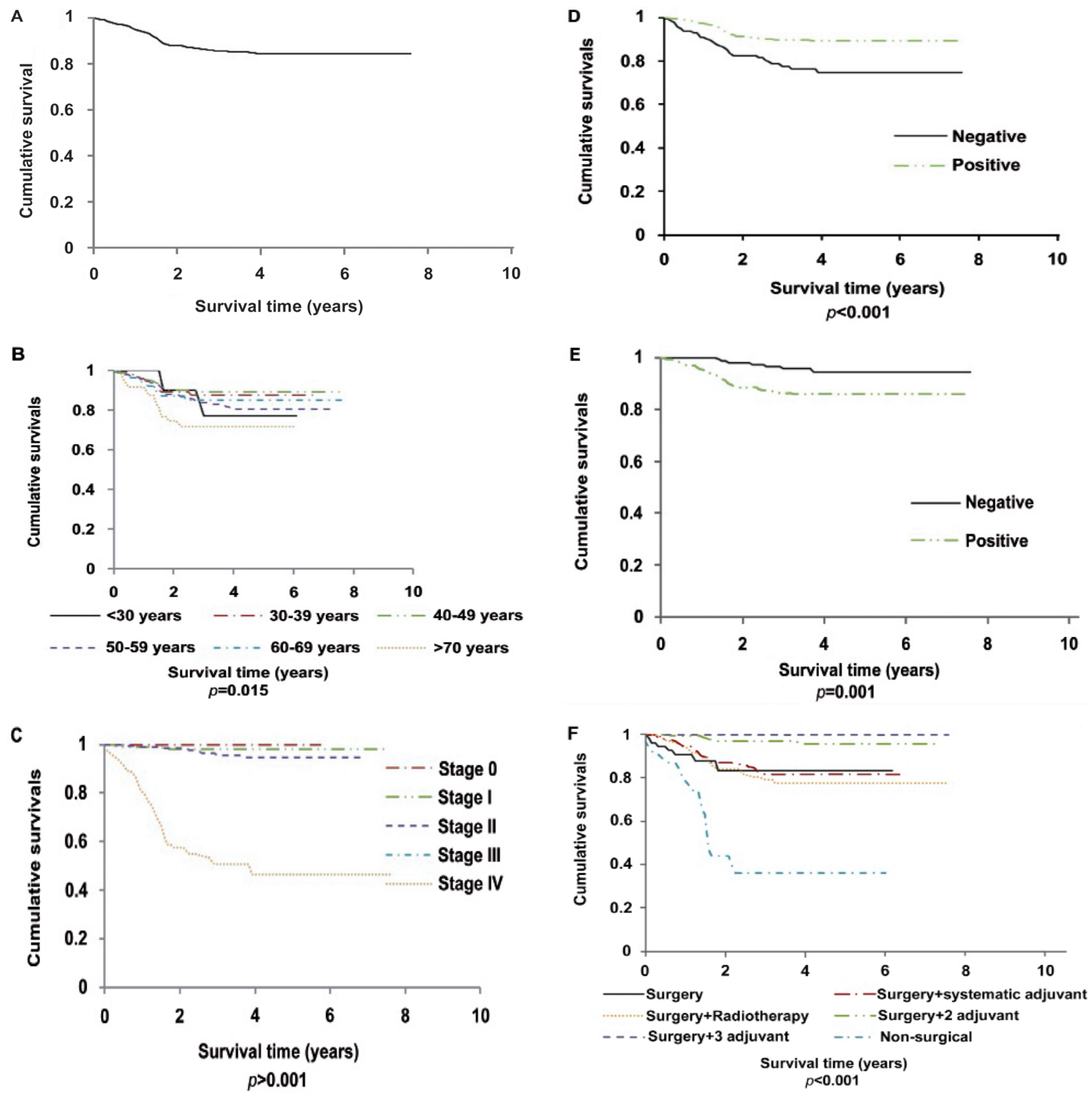

Figure 1 - Overall survival rate stratified by demographic or tumor characteristics. A) Overall survival rate; B) Survival rate by age group; C) Survival rate by tumor stage; D) Survival rate by ER status; E) Survival rate by lymph node status; and F) Survival rate by type of treatment.

Discussion. This study outline the distribution and survival of BC patients treated between 2011 and 2014 at 2 leading central public health providers in Amman, the capital of Jordan. The 5-year OS regardless of tumor and clinical characteristics, were $84 \%$ compared with $64 \%$, and $59.6 \%$ in the previous years. This highlights improvement in prognosis and survival. ${ }^{6,7}$ Improvement has also been witnessed in other countries. This highlights the promising advancement in cancer treatment and the increased awareness of screening programs on national levels. The 5-year OS in Iran was $0.8 \%$, in Morocco $0.9 \%$, and in Saudi Arabia was 82.6\%.23,24 Whereas the pooled 5-year OS in other studies conducted in 22 countries in the EMR was $0.7 \%$ (95\% CI: 0.7, 0.7). ${ }^{23}$ The variances in OS may highlight disparities and 
Table 3 - Covariates associated with overall mortality in the timedependent Cox model.

\begin{tabular}{|c|c|c|}
\hline Covariates & Hazard ratio $(95 \% \mathrm{CI})$ & $P$-value \\
\hline \multicolumn{3}{|c|}{ Main coefficients } \\
\hline TNM Staging & & $<0.001$ \\
\hline 1 & (reference) & \\
\hline 0 & NA (NA) & 1 \\
\hline 2 & $3.53(0.4,31.48)$ & 0.2 \\
\hline 3 & $17.45(1.72,177.36)$ & 0.016 \\
\hline 4 & $73.63(7.07,766.46)$ & $<0.001$ \\
\hline Nodal type & & 0.068 \\
\hline Negative & (reference) & \\
\hline Positive & $8.93(0.65,122.62)$ & 0.01 \\
\hline \multicolumn{3}{|c|}{ ER receptor type } \\
\hline Negative & (reference) & \\
\hline Positive & $0.31(0.18,0.54)$ & $<0.001$ \\
\hline Tumour size & $1.4(1.14,1.71)$ & 0.002 \\
\hline Age (years) & & 0.003 \\
\hline$>70$ & (reference) & \\
\hline$<30$ & $1.24(0.26,6.03)$ & 0.787 \\
\hline $30-39$ & $0.13(0.04,0.44)$ & 0.001 \\
\hline $40-49$ & $0.22(0.09,0.55)$ & 0.001 \\
\hline $50-59$ & $0.4(0.17,0.94)$ & 0.035 \\
\hline $60-69$ & $0.29(0.11,0.79)$ & 0.015 \\
\hline \multicolumn{3}{|c|}{ Time-varying coefficients } \\
\hline \multicolumn{3}{|c|}{ Nodal status } \\
\hline Negative & (reference) & \\
\hline Positive & $0.24(0.08,0.76)$ & 0.015 \\
\hline
\end{tabular}

inequity in cancer care across the area. This outlines the need for international screening programs to bridge inequity in cancer care across countries. ${ }^{25,26}$

It is of note that the survival rate of developing countries fall far behind developed countries. The 5 -year OS in Canada was $88 \%$, the United States was $91 \%$, European countries were $73.5-89.1 \%$, and Australia (2012-2016) was 91\%.23,28-31 Variation in survival rates amongst countries reflects the variation in the introduction of national detection programs and the early BC screening. Particularly, the detection of BC in early stages is associated with less aggressive treatment and better OS in addition to different life spans for the registry data available. This is in agreement with reports from Jordan over the years, where it has been shown that survival rates are improving.

Tumor stage and ER type were the most influential prognostic factors related to OS. Approximately $45 \%$ of patients were in the early stage, which was in line with the EMR countries, whereas in a study conducted in the US approximately $65 \%$ were in the early stage. ${ }^{28}$ Early detection of $\mathrm{BC}$ due to regular mammogram follow-ups in developed countries, in addition to lack of awareness and cultural beliefs in the EMR, such as Jordan, could explain these differences in $\mathrm{BC}$ epidemiology amongst various countries. ${ }^{25,32}$

In this study, the 5-year OS for patients in stage I was $98 \%$ and in stage IV was $46 \%$, whereas the 5 -year OS ranged from $82.7 \%$ to $96 \%$ for stage I and from $5.8 \%$ to $34.6 \%$ for stage IV were reported in previous studies conducted in Jordan. Such results should be underlined in national and public campaigns to spread awareness across community of necessity to seek help or diagnosis in early stages. ${ }^{6,7}$

Age was a significant predictor of OS. ${ }^{6,7}$ Consistent with some countries in the EMR, The lowest OS were in the group that was $<30$ years and the group that was $>70$ year. $^{32}$ Meanwhile, the highest OS in the age group of 40-49 years contributed to the greater access to detection programs and the public campaigns targeted at this age group.

Moreover, the lymph node status and ER receptor appeared to be prognostic factors in previous studies. This could be explained due to the aggressive nature of the disease in cases with positive lymph node and negative ER status. Patients with positive ER status respond more to hormonal therapy; therefore, targeted treatment selections based on ER status are crucial to ensure an effective response for BC..$^{33,34}$

Study limitations. First it is a retrospective study, where incomplete recording of demographic data presented considerable challenges at the time of data analysis. However, unrecorded data were possible were verified from the JCR records. The retrospective nature of the study cohort merits discussion of the effect of censoring. Potentially, information on time to outcome event were not available for all study participants (such as, censoring issue). However, this was accounted for by using time-dependent survival analysis.

All cancer cases diagnosed and treated in Jordan have been registered in the JCR since 1996, where the demographic characteristics and survival outcomes are reported. ${ }^{11}$ However, the registry does not collect treatment patterns and all prognostic factors. Bodies responsible for data collection and registry on the JCR should be enforced to enhance comprehensibility and accuracy. Yet, we believe that collecting data and matching information where possible with the hospital records enables a robust analysis and conclusions that are required to measure the survival rate of $\mathrm{BC}$. Therefore, the data in this study was based on 2 leading public hospitals (hospital-based registry) - the UJH and Bashir Hospital-which represent almost one third of the $\mathrm{BC}$ cases in Jordan (unpublished data from the 
cancer registry for 2011-2014). However, access to RMS and KHCC was not granted.

An $82.6 \%$ of the Jordanian citizens are living in the central area with small proportions residing in the north and south area. ${ }^{8}$ Therefore, people in the south and central are treated in Amman, while people in remote and rural areas have access to transportation to travel to the central area and get treatment in public hospitals. People residing in the north are treated in the King Abdallah Hospital, Amman Jordan which represents approximately $5 \%$ of the $\mathrm{BC}$ cases. However, they are transferred to Bashir Hospital for radiotherapy. Therefore, this hospital-based study represents the majority of average patients living in the central and south of Jordan.

Implication to health policy and practice. Improvement in BC survival was noticed over decades due to early detection of $\mathrm{BC}$ and improvement in treatments offered. This highlight potential strategy of shifting diagnosis of $\mathrm{BC}$ to its early stage with the expansion of early detection program. Efforts should be maximized to ensure the screening campaign reach out to remote governorates, refugee camps, and unprivileged communities near the boarders. Walk-in clinics and ambulatory screening units are advocated.

Since the tumor stage has been shown to be an important predictor of survival, early screening of $\mathrm{BC}$ is warranted to detect cancer in its early stage. Age was also found to influence survival rate. ${ }^{6,7}$ This must have great implications to the message sent to the public, where married aged women are seen as at a greater risk for worse prognosis. It is vital to highlight that time of diagnosis is crucial for better prognosis and observing any change. Therefore, public messages that highlight the need to seek help, regardless of age, are of vital importance.

Although the introduction of Jordan BC screening program in 2007 to raise the awareness on screening of $\mathrm{BC}$ in its early phases, ${ }^{35}$ still young female are reluctant to get screening due to social and cultural believes, which could hinder $\mathrm{BC}$ detection and thus delaying the diagnosis to later stage. ${ }^{36,37}$ Therefore, educating young female and women at school, Universities, and social media and break up the cultural barrier that could hinder reaching out for screening. Thus, future research should target screening program especially for high risk women (over 40 years old) and increase the public awareness on BC.

Moreover, complete recording of cancer patients' care and treatment pathways in hospitals, clinics and laboratories (histopathology reports) are vital for survival studies. Universal screening rather than opportunistic screening, particularly in communities where the culture might make females reluctant to seek early screening, could present an effective strategy to maximize survival and clinical outcomes.

In conclusion, Jordan witnessed an improvement in BC survival over the last decade. Tumor stage, ER status and age were significant prognostic factors. The prognosis of $\mathrm{BC}$ get worse with late stage and younger age highlighting that the implementation of early detection screening programs could help shift the diagnosis to early stages and could prolong survival.

Acknowledgment. We would like to thank Dr. Omar Nimri and Kamal Arqoub, who facilitated obtaining and verification of the study data from the JCR. We would like to thank ProofReading-Service.com for English language editing.

\section{References}

1. Bray F, Ferlay J, Soerjomataram I, Siegel RL, Torre LA, Jemal A. Global cancer statistics 2018: GLOBOCAN estimates of incidence and mortality worldwide for 36 cancers in 185 countries. CA Cancer J Clin 2018; 68: 394-424.

2. Kulhanova I, Bray F, Fadhil I, Al-Zahrani AS, El-Basmy A, Anwar WA et al. Profile of cancer in the Eastern Mediterranean region: The need for action. Cancer Epidemiol 2017; 47: 125-132.

3. Khader YS, Sharkas GF, Arkoub KH, Alfaqih MA, Nimri OF, Khader AM. The epidemiology and trend of cancer in Jordan, 2000-2013. J Cancer Epidemiol 2018; 2018: 1-7.

4. World Health Organisation. World cancer report. International Agency for Research on Cancer. [Updated 2020. Accessed 2020 May 22]. Available from: https://publications.iarc.fr/586

5. World Health Organisation. Noncommunicable diseases (NCD) country profiles. [Updated 2018. Accessed 2020 December 25]. Available from: https://www.who.int/nmh/ countries/jor_en.pdf

6. Tarawneh MA, K. Sharkas, G. Epidemiology and survival analysis of Jordanian female breast cancer patients diagnosed from 1997 to 2002. Middle East J Cancer 2011; 2: 71-80.

7. Arkoob K, Al-Nsour M, Al-Nemry O, Al-Hajawi B. Epidemiology of breast cancer in women in Jordan: patient characteristics and survival analysis. East Mediterr Health $J$ 2010; 16: 1032-1038.

8. Abdel-Razeq H, Mansour A, Jaddan D. Breast cancer care in Jordan. JCO Glob Oncol 2020; 6: 260-268.

9. The Jordan Times. Patient referral to KHCC ongoing — health ministry. [Updated 2018. Accessed 2018April 14]. Available from: https://www.jordantimes.com/news/local/patientreferral-khcc-ongoing-\%E2\%80\%94-health-ministry

10. Jordan Times. International committee to study cost of cancer treatment in Jordan. [Updated 2018. Accessed 2018 March 12]. Jordan Times. Available from: https://www.jordantimes. $\mathrm{com} /$ news/local/intl-committee-study-cost-cancer-treatmentjordan

11. Ministry of Health. Non-Communicable Diseases Directorate. [Updated 2016. Accessed 2020 April 20]. Available from: http://www.moh.gov.jo/Echobusv3.0/SystemAssets/a05a084b3781-4979-a217-2184d5d57ede.pdf 
12. Jordan University Hospital. University of Jordan Hospital, About Us. [Updated 2019. Accessed 2020 December 2]. Available from: http://hospital.ju.edu.jo/medical/juhospital/ Home.aspx

13. Bland JM, Altman DG. The logrank test. BMJ 2004; 328: 1073.

14. Clark TG, Bradburn MJ, Love SB, Altman DG. Survival analysis part I: Basic concepts and first analyses. Br J Cancer 2003; 89: 232-238.

15. Bradburn MJ, Clark TG, Love SB, Altman DG. Survival analysis part II: multivariate data analysis--an introduction to concepts and methods. Br J Cancer 2003; 89: 431-436.

16. Chen H-L, Zhou M-Q, Tian W, Meng K-X, He H-F. Effect of age on breast cancer patient prognoses: a population-based study using the SEER 18 database. PloS one 2016; 11: e0165409.

17. Martínez ME, Unkart JT, Tao L, Kroenke CH, Schwab R, Komenaka I, et al. Prognostic significance of marital status in breast cancer survival: A population-based study. PloS one 2017; 12: e0175515.

18. Obeidat F, Ahram M, Al Khader A, Battah K, Alchalabi M, Melhem JM, et al. Clinical and histopathological features of breast cancer in Jordan: Experience from a tertiary care hospital. J Pak Med Assoc 2017; 67: 1206-1212.

19. Zheng YZ, Wang L, Hu X, Shao ZM. Effect of tumor size on breast cancer-specific survival stratified by joint hormone receptor status in a SEER population-based study. Oncotarget 2015; 6: 22985-22995.

20. Sollie M, Bille C. Smoking and mortality in women diagnosed with breast cancer-a systematic review with meta-analysis based on 400,944 breast cancer cases. Gland surgery 2017; 6: 385-393.

21. Schuil H, Derks M, Liefers GJ, Portielje J, van de Velde C, Syed $\mathrm{B}$, et al. Treatment strategies and survival outcomes in older women with breast cancer: A comparative study between the FOCUS cohort and Nottingham cohort. J Geriatr Oncol 2018; 9: 635-641.

22. Bellera CA, MacGrogan G, Debled M, de Lara CT, Brouste V, Mathoulin-Pelissier S. Variables with time-varying effects and the Cox model: some statistical concepts illustrated with a prognostic factor study in breast cancer. BMC Med Res Methodol 2010; 10: 20.

23. Hassanipour S, Maghsoudi A, Rezaeian S, Arab-Zozani M, Mokhtari AM, Abdzadeh E, et al. Survival rate of breast cancer in Eastern Mediterranean region countries: a systematic review and meta-analysis. Ann Glob Health 2019; 85:138.

24. Harvard Medical School. Health system strengthening and breast cancer care in the Middle East. [Updated 2018. Accessed 2020 March 2]. Available from: https://ghd-dubai.hms.harvard. edu/files/ghd_dubai/files/breast_cancer_proceedings.pdf

25. World Health Organization. Strategy for Cancer Prevention and Control in the Eastern Mediterranean Region 2009-2013. [Updated 2013. Accessed 2020 August 10]. https://apps.who. int/iris/handle/10665/116672, 2013
26. Znaor A, Fouad H, Majnoni d'Intignano F, Hammerich A, Slama S, Pourghazian N, et al. Use of cancer data for cancer control in the Eastern Mediterranean Region: Results of a survey among population-based cancer registries. Int J Cancer 2021; 148: 593-600.

27. Canadian Cancer Society. Breast Cancer Statistics: Incidence and mortality. [Updated 2020. Accessed 2021 January 31]. Available from: https://www.cancer.ca/en/cancer-information/ cancer-type/breast/statistics/?region=on

28. American Cancer Society. Breast cancer (Facts and figures 2019-2020). [Updated 2020. Accessed 2020 July 19]. Available from: https:/www.cancer.org/content/dam/cancer-org/ research/cancer-facts-and-statistics/breast-cancer-facts-andfigures/breast-cancer-facts-and-figures-2019-2020.pdf

29. Gliniewicz A, Zielińska A, Kwiatkowska K, Dudek-Godeau D, Bielska-Lasota M. Survival in women diagnosed with breast and cervical cancer in Poland - compared to European countries, based on CONCORD - 3 Programme. Przegl Epidemiol 2018; 72: 499-508.

30. Dafni U, Tsourti Z, Alatsathianos I. Breast cancer statistics in the European Union: incidence and survival across European countries. Breast Care (Basel) 2019; 14: 344-353.

31. Sankaranarayanan R, Swaminathan R, Brenner H, Chen K, Chia KS, Chen JG et al. Cancer survival in Africa, Asia, and Central America: a population-based study. Lancet Oncol 2010; 11: 165-173.

32. Maajani K, Khodadost M, Fattahi A, Pirouzi A. Survival rates of patients with breast cancer in countries in the Eastern Mediterranean Region: a systematic review and meta-analysis. East Mediterr Health J 2020; 26: 219-232.

33. Parks RM, Green AR, Cheung KL. The impact of tumour biology on the management of primary breast cancer in older women-based on a research programme in Nottingham. Ann Breast Surg 2021; 5: 5.

34. AlZaman AS, Mughal SA, AlZaman YS, AlZaman ES. Correlation between hormone receptor status and age, and its prognostic implications in breast cancer patients in Bahrain. Saudi Med J 2016; 37: 37-42.

35. Jordan Breast Cancer Program. Jordan Breast cancer program brief. King Hussein Cancer Foundation 2019. [Updated 2019. Accessed 2020 April 20]. Available from: http://www.jbcp.jo/ about $/ 15$

36. Al-Mousa DS, Alakhras M, Hossain SZ, Al-Sa'di AG, Al Hasan M, Al-Hayek Y, et al. Knowledge, attitude and practice around breast cancer and mammography screening among Jordanian women. Breast Cancer 2020; 12: 231-242.

37. Al Dasoqi K, Zeilani R, Abdalrahim M, Evans C. Screening for breast cancer among young Jordanian women: ambiguity and apprehension. Int Nurs Rev 2013; 60: 351-357. 